\title{
Does Owner-Occupied Housing Affect Neighbourhood Crime?
}

\author{
by \\ Jørgen Lauridsen, \\ Niels Nannerup \\ and \\ Morten Skak
}

Discussion Papers on Business and Economics

No. $19 / 2013$

FURTHER INFORMATION

Department of Business and Economics

Faculty of Business and Social Sciences University of Southern Denmark Campusvej 55

DK-5230 Odense M

Denmark

Tel.: +4565503271

Fax: +4565503237

E-mail: lho@sam.sdu.dk

http://www.sdu.dk/ivoe 


\title{
Does Owner-Occupied Housing Affect Neighbourhood Crime?
}

\section{Jørgen Lauridsen (1), Niels Nannerup (2) and Morten Skak (2).}

(1): Corresponding author: Department of Business and Economics \& Centre of Health Economics Research (COHERE), University of Southern Denmark, Campusvej 55, DK-5230 Odense M, Denmark, E-mail jtl@sam.sdu.dk, homepage http://www.sdu.dk/ansat/jtl.aspx.

(2): Department of Business and Economics, University of Southern Denmark

Aknowledgement: The paper was written as a part of the Center for Housing and Welfare RealDania Research Project. Economic support from RealDania is acknowledged.

Key Words: Housing market; Violence Crime; Simple Crime; Neighbourhood Deprivation

JEL Classifications: C21; C23; C33; K42; P25; R31

\begin{abstract}
Economic as well as sociological theory bring some support to the hypothesis that personal home ownership per se makes individuals more responsible to society values and hence less inclined to commit offences against property or commit other kinds of crimes. Departing from this hypothesis, the present study seeks to provide empirical evidence for a link between levels of crime and local residential ownership rates. In the framework of a linear regression model and based on Danish municipality data, we establish empirical evidence for a negative relationship between local home ownership rates and local crime rates even when controlling for a broad range of economic and demographic variables.
\end{abstract}




\section{Introduction}

Researchers in social capital have recently identified a range of linkages between the physical environment and the social interactions among individuals. Among other issues, the impacts of home ownership on social connection are examined. Home owners appear to have a high stake in protecting the local community, and, compared to home renters, tend to put more effort in the upkeep and appearance of a neighbourhood. There are several reasons for this. For instance, home owners, unlike home renters, have made financial investments in their dwellings, and they furthermore appear more stationary than home renters. These stakes in the property and social community may again lead to activities and behaviour that serve to reduce vandalism, theft and other crimes in the local area and generally increases social interaction and responsibility between residents. Several studies document a range of social community effects from home ownership. They include, among others, Glaeser and Sacerdote (2000), Perkins et al. (1996), Rohe and Basolo (1997), and White (2001).

The general aim of this paper is to identify empirical relationships between crime rates and a range of economic and socio-economic variables for Denmark in the period 1997 - 2003. In particular, we are interested in examining the hypothesized relationship between crime and home ownership while controlling for other variables having appeared as significant determinants for crime rates in previous studies (including unemployment levels, average income, percentage of youngsters etc.).

Regarding crime in particular, a number of studies provide empirical evidence for an inverse relationship between home ownership and various forms of crime. While Ross (1977) found that home ownership rates in the US were negatively correlated with burglary, auto theft and other theft rates, Krause (1976) concluded that home ownership tended to decrease levels of violence in US 
cities. Negative correlations between crime and home ownership rates are also documented in recent studies; see for example White (2001) and Ludwig et al. (2001).

For policy reasons it is generally worthwhile to seek solid insights in the relationships between crime and owner structure at housing markets. Obviously, if negative linkages exist between various types of crime of residents and home ownership to dwellings in neighbourhoods, powerful public policies in combating crime could be to offer (publicly owned) rented dwellings for sale to residents or to move more troublesome criminals to certain private-market housing. As an example, Ludwig et al. (2001) study groups of high poverty teen families from Baltimore neighbourhoods having received subsidies and public counselling to move to private-market housing in low poverty areas. The results of this study suggest large reductions in violence crimes in these families.

In the present analysis we establish two linear models with crime rates as the dependent variable. Based on cross section data for Danish municipalities, we find significant negative relationships between crime and home ownership for property crime as well as violence crimes. Furthermore, the results show significance of such variables as unemployment levels and the share of urban population in a municipality. Therefore, the present study also adds to studies addressing the relationship of crime to these variables.

\section{Data and variables}

The data to be applied are aggregate cross section data observed for 270 Danish municipalities (five municipalities on the island of Bornholm were omitted due to data problems) annually from 1997 to 2003. Data were collected from five sources: The Statistical Bank at Statistics Denmark, the Key Figure Base at the Ministry of the Interior, the Ministry of Urban and Housing Affairs' (2000) 
report on regulation of housing rents, and the Danish Tax Authority’s (2004) report on property sales prices.

Drawing upon suggestions from theoretical as well as empirical research, we test a number of determinants as candidates for being significantly explanatory factors for Danish crime rates. According to theory of economics of crime, such variables include average income level in municipalities, the proportion of individuals receiving social benefits, and the proportion without education. In line with e.g. Becker (1968) these factors reflect the fact that the expected return from crime net of the risk of being caught and punished will be higher for low income groups, as punished individuals typically risk losing jobs and status. Furthermore, we control for unemployment variation although empirical evidence on the impacts of unemployment on crime is somewhat mixed. A number of studies based on US data support a positive relation between deteriate labour market conditions and crime rates, see for example Levitt (1996) and Gould et al. (2002). On European data, neither Entorf and Spengler (2000) nor Rodriguez (2003) find support for the hypothesized relationship. However, a recent study for a panel of Swedish counties shows that unemployment has a positive and significant effect on some property crime, see Edmark (2005).

We also control for the proportion of young (17 to 25 year old) people in the municipalities, the proportion of citizens from third countries, the rate of asylum seekers, and the divorce rate in municipalities. The variation of these demographic traits all account for much of the variation in crime rates in Denmark.

In the analyses of the present study, the above mentioned variables are related to crime rates during two independent regressions where 'simple property crimes' and 'violence crimes', respectively, are chosen as dependent variables. In the Danish statistics, the simple property crime variable 
includes burglary, car and bike theft, theft from shops, and theft by means of fraud. Notice, in contrast, that robbery is not treated as simple property crime, the argument being that (at minimum) a threat about the use of violence is present under robbery offences. Robberies are therefore included in the variable violence crime, which also includes assaults, rape and homicide.

It should be emphasized that the applied crime rates are based on reported crimes per 1.000 inhabitants rather than crimes actually committed. There are reasons to believe, however, that reported crimes hardly distort the real picture of Danish crimes. In Denmark it is a condition for receiving insurance compensation that a crime has been reported. Moreover, even though discrepancies may exist for certain types of crimes between the number of reported and the true number of crimes, this will be a minor problem for the present analysis, as long as the relative changes in reported crimes are followed by (approximately) the same changes in true crimes.
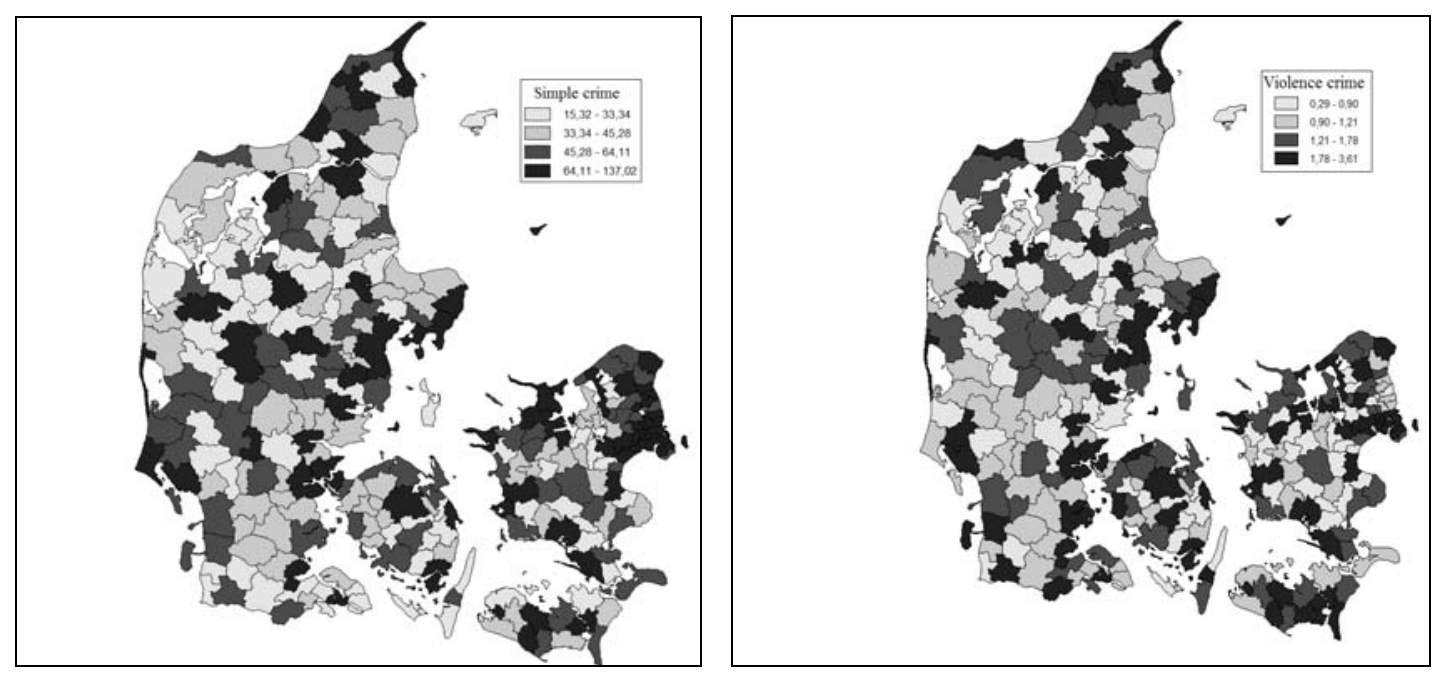

Figure 1. The distribution of simple property crime and violence crime in Danish municipalities 2003 (number per 1.000 inhabitants).

Figure 1 shows the distribution of the two crime rates across municipalities for the year 2003, while Figure 2 shows the aggregate crime rates for Denmark for the period 1994-2003. The distributions 
of property crime and violence crime show the well-known pattern of a high variation across the country with a concentration of crime in and around big cities and relatively low levels at countryside areas with low population density. Furthermore, some variation over time is indicated from Figure 2, which also reveals a slightly decreasing tendency for property crimes in Denmark whereas violence crimes have increased during the period. Actually, high variation of crime rates over time and space is a common phenomenon across countries as well as across big cities, see Glaeser et al (1996) for at thorough analysis of this issue based on US data.
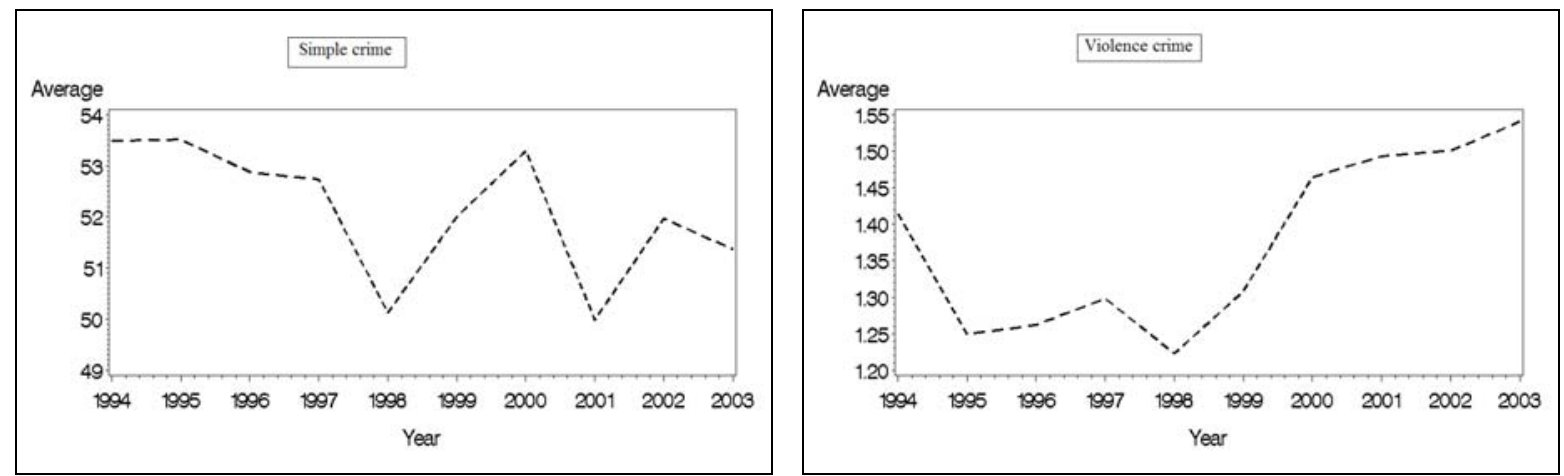

Figure 2. Simple and violence crimes in Denmark 1994 - 2003 (number per 1.000 inhabitants).

\section{Results}

Given the data and the specifications, we choose a simple linear relation to carry out a preliminary evaluation of Danish crime rates patterns and in particular to obtain a statistical indication of a significantly negative relationship between home ownership and the two main groups of crime. The estimated models are outlined in Table 1. 
The assumed relationships between the two crime rates and the variables outlined in Table 1 are obviously evaluated, given that the parameters of either specification are estimated to be either significant at a one percent level of significance or insignificant even at a ten per cent level.

Table 1. Estimated regression models for property crime and violence crimes.

\begin{tabular}{|l|l|l|}
\hline & Reported property crimes & Reported violence crimes \\
\hline Percentage of citizens in own home & $-0.48^{*}$ & $-0.02^{*}$ \\
& $(0.05)$ & $(0.002)$ \\
\hline Percentage of citizens in subsidized housing & 0.02 & $-0.01^{*}$ \\
& $(0.06)$ & $(0.003)$ \\
\hline Percentage of citizens living in city areas & $0.24^{*}$ & $0.01^{*}$ \\
& $(0.03)$ & $(0.001)$ \\
\hline Average income & $146.51^{*}$ & -0.54 \\
& $(30.48)$ & $(1.37)$ \\
\hline Percentage of citizens aged 17-25. & $4.31^{*}$ & 0.01 \\
& $(0.26)$ & $(0.01)$ \\
\hline Percentage of citizens from regions outside & 0.04 & $0.01^{*}$ \\
EU, Scandinavia, North America & $(0.03)$ & $(0.001)$ \\
\hline Number of asylum seekers & 0.01 & $0.001^{*}$ \\
& $(0.01)$ & $(0.0001)$ \\
\hline Percentage of citizens unemployed & $0.61^{*}$ & -0.01 \\
& $(0.17)$ & $(0.01)$ \\
\hline Percentage of citizens receiving social & $0.65^{*}$ & $0.04^{*}$ \\
benefits & $(0.20)$ & $(0.01)$ \\
\hline Percentage of citizens divorced & $5.47^{*}$ & $0.10^{*}$ \\
& $(0.33)$ & $(0.01)$ \\
\hline Percentage of citizens without education & 0.02 & $0.02^{*}$ \\
& $(0.07)$ & $(0.004)$ \\
\hline Intercept & $-40.56^{*}$ & 0.51 \\
& $(10.26)$ & $(0.46)$ \\
\hline R & 0.71 & 0.37 \\
\hline
\end{tabular}

Note: Figures in parentheses are standard errors. Level of significance at $1 \%$ indicated by *. No coefficients were significant at levels $5 \%$ or $10 \%$. Data are for 270 Danish municipalities 19942003.

Considering selected parameters in the models, the income related variables average income, unemployment rates and social benefit rates all prove to affect property crimes significantly. The analysis thus provides evidence in support of hypotheses focusing on income related factors motivated by economic theory as the basic explanations behind property crimes. In relation to this, 
it is also noteworthy that neither average income nor unemployment have significant effects on violence crimes, whereas the social benefit percentage proves significant. Moreover, the two migration variables show the same pattern of being significant for violence crimes only. This suggests that non-economic factors of social marginalisation may provide better explanations of violence crimes. This is in accordance with a number of Danish studies, which have revealed lower social connection for the group of individuals on social benefits than for individuals being unemployed.

In accordance with other investigations, the results of the present study also confirm significant 'city-effects' for both types of crimes. It is well documented from other country studies that there is more crime in city areas than in country-side areas (Glaeser and Sacerdote, 1999) and, further, that within bigger cities hot spot areas of crime can be identified. (Grogger and Willis, 2000) The results thus indicate the same tendency for Denmark. Furthermore, as expected, percentage of young people proves significant only for property crime, while it is insignificant for violence crimes, supporting the conventional wisdom that crimes committed by most youngsters fall in less serious categories and may be seen as a temporary phenomenon for a majority of these individuals.

Turning to the main issue of home ownership, highly significant negative effects are found for both models; the results thereby suggest a clear negative correlation between crime and owner-occupied residence for Denmark.

\section{Conclusion}

A main contribution of the present study has been to examine the relationship between home ownership and crime rates on Danish data in order to provide statistical evidence regarding various 
hypotheses, grounded in economic theory, which hypothesise a negative linkage between crime rates and the percentage of home owners in a neighbourhood.

Our results provide evidence of such a negative relationship for the years considered. For property crimes as well as violence crimes, home ownership is found to have negative and significant effects on both crime rates. However, the negative relationship between home ownership and crime may stem from other reactions by individuals than raises in social connection and citizenship from high ownership rates. Another perspective could be an adverse dependency, meaning that crime rates affects home ownership in the local community in the sense that high crime rates lead to a general migration away from neighbourhoods for residents demanding high safety and pleasant surroundings in their daily life. Among such groups, households with high preferences for home ownership may well be overrepresented, for example due to the aforementioned high stakes in owned dwelling. Therefore, whether crime rates influence the percentage of home owner rather than home ownership determining crime is still an open question; more analysis is necessary to cast light on these causal linkages for the Danish case.

\section{References}

Becker, G. S. (1968), Crime and Punishment: an Economic Approach, Journal of Political Economy, 81, pp. $526-536$.

Edmark, K. (2005). Unemployment and Crime: Is there a Connection?, Scandinavian Journal of Economics 107(2), pp. 353-373.

Entorf, H. and H. Spengler. (2000). Socioeconomic and Economic Factors of Crime in Germany: Evidence from Panel Data of the German States, International Review of Law and Economics 20, pp. $75-106$. 
Gould, E. D., B. A. Weinberg, and D. Mustard (2002). Crime Rates and Local Labor Opportunities in the United States: 1979 - 1995, Review of Economics and Statistics 84, pp.

Glaeser, E: L., B. Sacerdote and J. A. Scheinkman (1996). Crime and Social Interactions, The Quarterly Journal of Economics 111, pp. 508 - 548..

Glaeser, E: L. and B. Sacerdote (2000). The Social Consequences of Housing, Journal of Housing Economics 9, pp. 1-23.

Krause, D.R. (1976). Violence: A Territorial Analysis. Unpublished doctoral dissertation, University of Illinois, Chicago Circle.

Levitt, S. D. (1996). The Effect of Prison Population Size on Crime Rates: Evidence from Prison Overcrowding Litigation, Quarterly Journal of Economics, 111, 319-352.

Ludwig, J., G.J. Duncan, and P. Hirschfield (2001). Urban Crime and Juvenile Crime: Evidence from a Randomized Housing Mobility Experiment, Quarterly Journal of Economics, 116, pp. 655679.

Perkins, D.D., B.B. Brown, and R.B. Taylor (1996). The Ecology of Empowerment: Predicting Participation in Community Organisations, Journal of Social Issues, 52, pp. 85-110.

Rohe, W.M. and V. Basolo (1997). Long-term effects of homeownership on the self-perceptions and social interaction of low-income persons. Environment and Behaviour, 29, 793-819.

Ross, M. (1977). Economics, Opportunity and Crime, Montreal, Canada: Renouf.

White, G. F. (2001). Home Ownership - Crime and the Tipping and Trapping Processes, Environment and Behavior, Vol. 33, No. 3, May 2001, pp. 325-342. 